\title{
A CASE OF DISSECTING ANEURYSM IN A CHLD
}

\author{
BY \\ P. N. COLEMAN \\ From the Friarage Hospital, Northallerton, Yorks
}

(RECEIVED FOR PUBlication MAY 4, 1955)

A case is reported of sudden death in a girl aged 10 years due to the rupture of a dissecting aneurysm of the ascending aorta. Cases of dissecting aneurysm have been very rarely reported in children, and the occasional occurrence of such cases has added interest because it strengthens the view that dissecting aneurysms in younger patients are of congenital origin.

\section{Case Report}

The patient, a girl aged 10 years, was said to have always been delicate, subject to colds and the like. At the age of 3 years she had meningitis which left her with a squint, later corrected at operation. On the afternoon of her death she played a game of "tig" with her friends, running about continuously for half an hour. She then suddenly ran into her home and collapsed semi-conscious on to the floor. By the time the family doctor arrived she was making a good recovery but complaining of pains in the chest and abdomen. Physical examination was negative except for signs of a mild bronchitis, so the patient was put to bed, the doctor saying that he would visit her again the next day. During the evening the child was described as very lively, but before she went to sleep beside her mother she again complained of pain, this time in the chest and neck. Waking in the morning, the mother found her daughter dead beside her.

Necropsy was performed at the request of the coroner. Nothing abnormal was noted at the external examination. The cause of death was found to be a haemopericardium which had originated in a small external tear in a dissecting aneurysm limited to the ascending aorta. On opening the heart and aorta, a horizontal split was seen in the wall of the aorta situated $2 \frac{1}{2} \mathrm{~cm}$. above the aortic valves (Fig. 1). Dissection had occurred into the outer third of the media (Fig. 2). There was some dilatation of the ascending aorta, the lumen being $2.8 \mathrm{~cm}$. in diameter. At a point just beyond the origin of the subclavian artery the arch of the aorta showed a degree of constriction, the lumen being reduced to $9 \mathrm{~mm}$. in diameter to open out again so that in the descending thoracic aorta the diameter was $1.5 \mathrm{~cm}$. This minor degree of coarctation was not associated with any development of collateral circulation. The heart weighed $200 \mathrm{~g}$. The foramen ovale was patent $(8 \mathrm{~mm}$. in diameter). There was also an inconspicuous cordlike thickening running just below, and parallel to, the free margin of the aortic valves (Fig. 1). The only other abnormality noted at necropsy concerned the kidneys. The right kidney was hypoplastic and lay on the pelvic wall in relation to the external iliac artery. The left kidney was in the normal position and showed a compensatory hyperplasia.

Sections taken from the wall of the aorta showed an extensive degeneration of the media which had its greatest development in the region within $3 \mathrm{~cm}$. of the aortic valves. Here the wall of the aorta contained clefts and cyst-like spaces. The degeneration particularly affected the elastic tissue (Figs. 3 and 4). Appropriately stained sections showed that in the first $3 \mathrm{~cm}$. of the aorta elastic fibres were virtually confined to the outer third of the media, and that here they were separated and broken up, and in places interrupted by the cyst-like spaces. In the distal part of the ascending aurta and in the arch, the elastic tissue extended throughout the wall, but showed separation and fragmentation of the fibres. In the sections stained by haematoxylin and eosin (Fig. 5) relatively normal smooth muscle could be seen, the individual fibres, in places, being separated by empty spaces staining faintly blue. There was a complete absence of any signs of inflammatory reaction. Vasa vasorum were frequent, but only in the first $3 \mathrm{~cm}$. of the aorta. In places these vessels, having entered the outer third of the media, showed local dilatations. Sections were also stained by Southgate's mucicarmin and by the P.A.S. techniques because a number of the reports on medial degeneration of the aorta describe a mucinous degeneration. Mucin was not demonstrated.

The pulmonary artery in the region just above the valves showed, in a minor degree, similar degenerative changes to those observed in the aorta, the elastic fibres being separated and fragmentated (Fig. 6). Sections from the aortic valves showed that the cord-like thickening referred to above was composed of oedematous fibrous tissue.

\section{Discussion}

It is now well recognized that dissecting aneurysm sometimes occurs in the young. Schnitker and Bayer (1944), considering 580 cases of dissecting aneurysm gathered from the litera- 


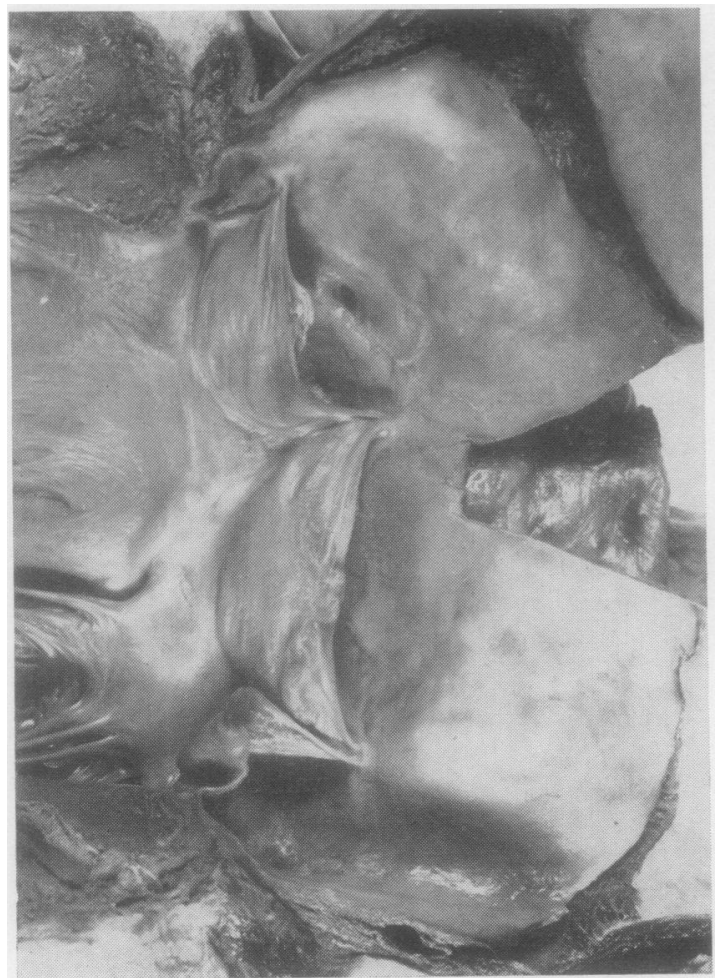

FIG. 1.-Aortic valves and beginning of the ascending aorta showing the horizontal split in the wall of the aorta and the cord-like thickening running below the free margin of the valves (approx. natural size).

ture, found that in 141 cases $(24 \%)$ the patients were less than 40 years of age. Gore (1953) collected 32 cases of dissecting aneurysm in patients under 40 years of age from the records of the U.S. Armed Forces Institute of Pathology. The condition, however, has rarely been reported in children: Schnitker and Bayer's survey included only four cases in the age group 1-10 years.

Brief details are given below of cases that have been reported in children and adolescents. The details for the cases reported before 1906 are those quoted in the reviews of the literature given in the papers referred to above, and in papers by Bronson and Sutherland (1918) and by Klotz and Simpson (1932).

Bronson and Sutherland (1918) described what must be one of the youngest cases. The patient, a boy, showed clinical signs of aneurysm at the age of $4 \frac{1}{2}$ years. Rupture of a dissecting aneurysm into the wall of a previously existing saccular aneurysm of the arch of the aorta occurred at the age of 6 years. A minor degree of coarctation was present, and there were other developmental defects the significance of which will be discussed below. Cases of dissecting aneurysm of the arch of the aorta in two boys both aged 8 years and a 으․ girl aged 9 years were reported by C. Rokitansky (1838), K. Rokitansky (1852), and Oppenheimer (1905). In K. Rokitansky's case there were developmental defects: congenital narrowing of

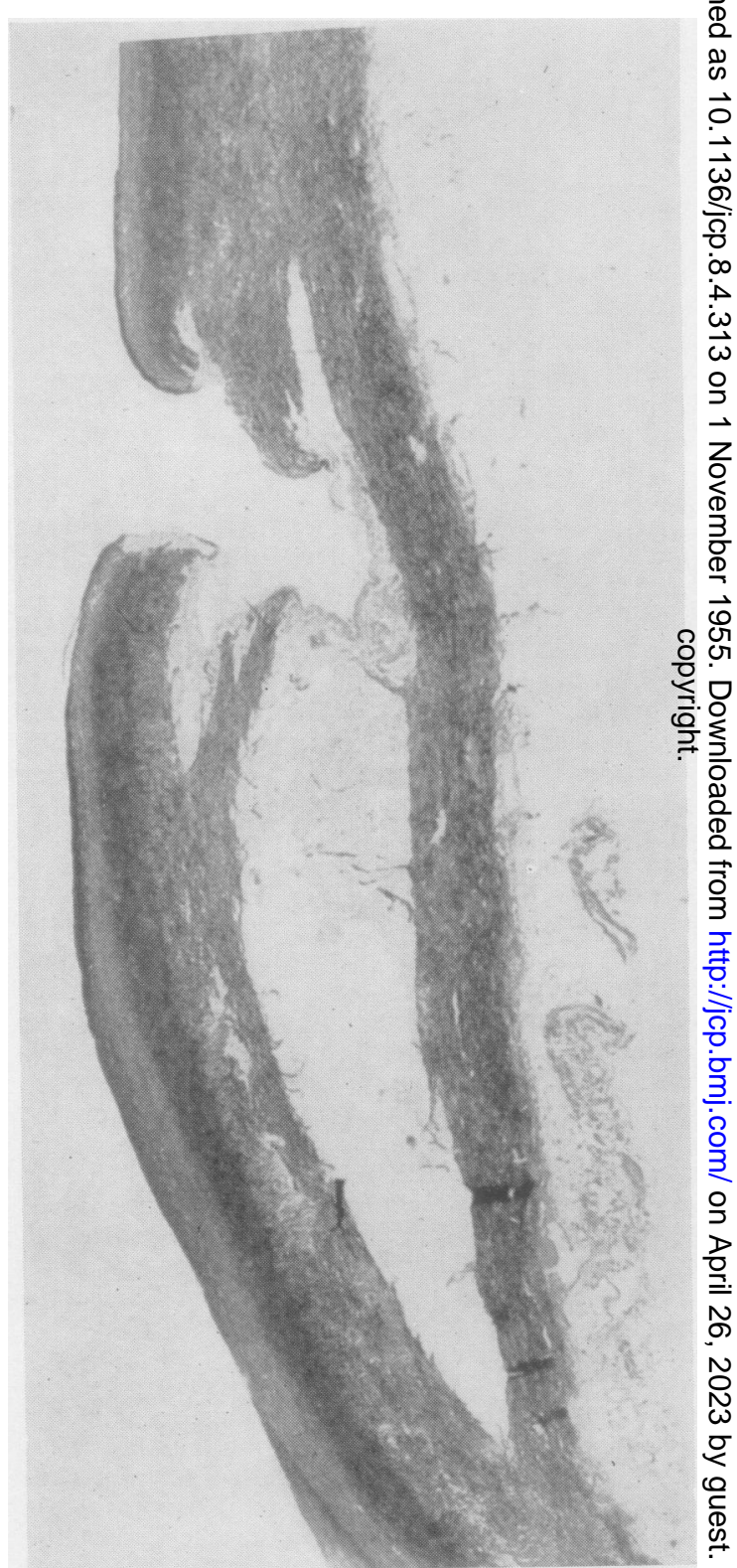

FIG. 2. Section of the wall of the aorta showing the beginning of the dissecting aneurysm into the outer third of the media $(\times 200$ Weigert's elastic stain and neutral red). 
the aorta, a ventricular septal defect, and deformity of the pulmonary artery.

Cases occurring in slightly older patients include those reported by Horder (1907) in a boy aged 11 years, dissection occurring into a previously formed saccular aneurysm of the aortic arch ; by Wasastjerna (1903) in a boy aged 13 years with an extreme degree of coarctation ; and by Gardner, Galbraith, and Hardwick (1939). In Gardner's case, a boy of 15 , the aneurysm was described as the largest dissecting aneurysm that had ever been reported, the dissection extending into the main arterial trunks of the limbs. There was also a dissecting aneurysm of the pulmonary artery, which is of interest in view of the finding of medial degeneration of the pulmonary artery in the present case.

It is generally agreed that the degeneration of the media is the cause of nearly all dissecting aneurysms, including those occurring in the young. Of the cases quoted above, medial degeneration was mentioned in the case reports by Bronson

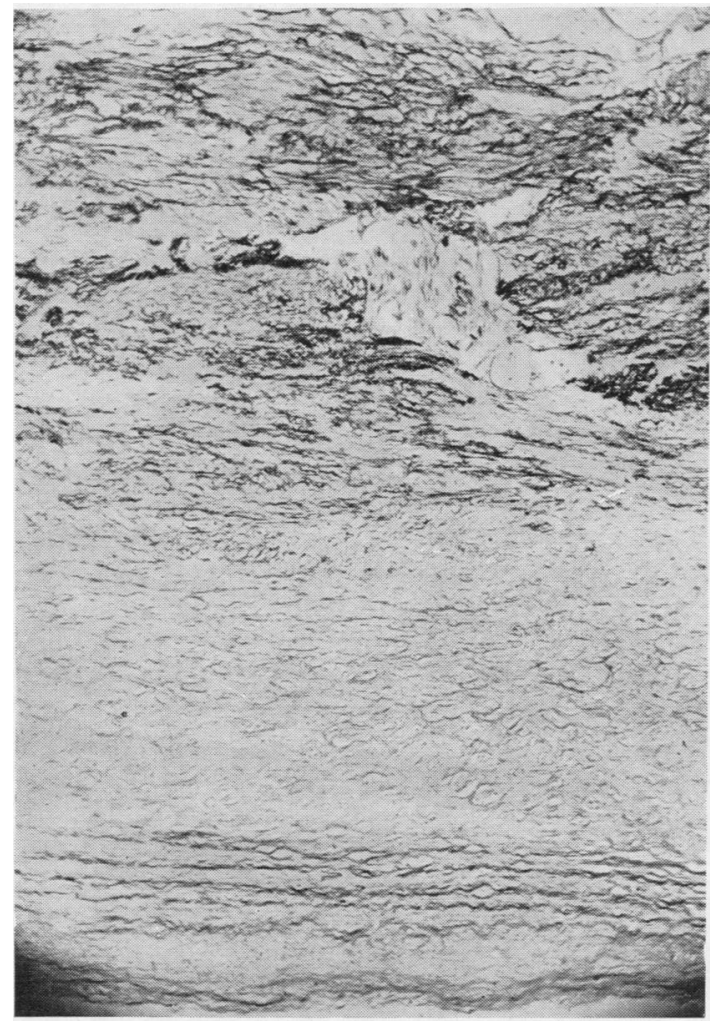

FIG. 3.-The wall of the aorta $2 \mathrm{~cm}$. above the valves showing disappearance of elastic from the inner two-thirds of the media and fragmentation and separation of the fibres in the outer third ( $\times 75$ Weigert's elastic stain and neutral red).

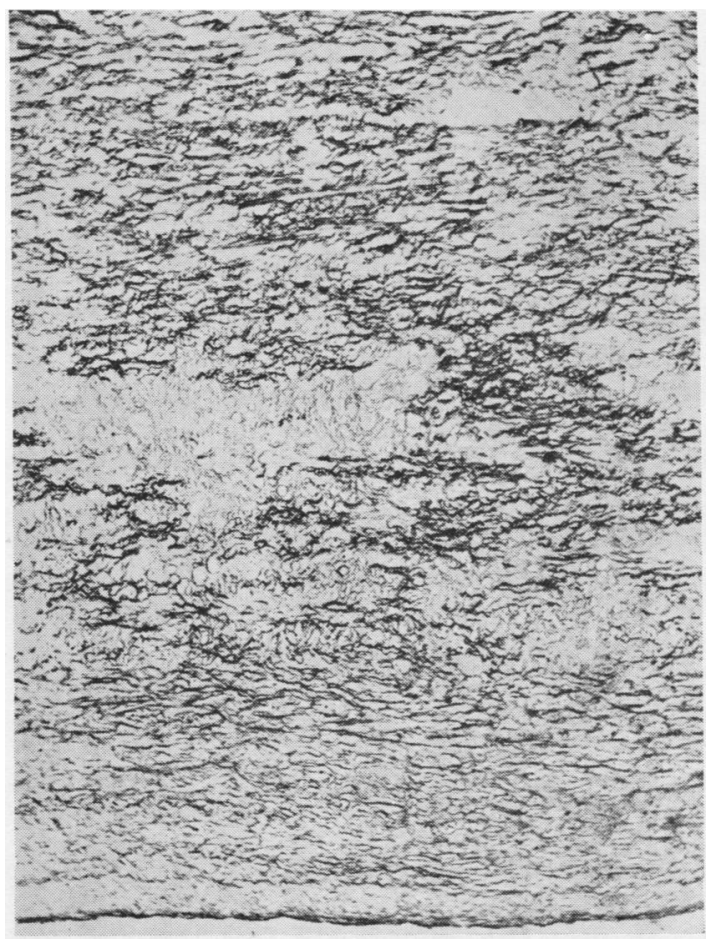

FIG. 4.-The wall of the aorta just distal to the split. Severe degeneration of the elastic tissue but less so than in Fig. 3. $(\times 75$ Weigert's elastic stain and neutral red).

and Sutherland, Oppenheimer, and Gardner et al. The severe medial degeneration observed in the present case has been described. Degeneration particularly affected the elastic fibres, and it is of interest that Gore found that in young patients degeneration of the media was primarily that of elastic tissue whereas in older patients it affected the muscle.

The aetiology of medial degeneration may be reviewed briefly. It seems probable that it differs, when it occurs in later life, the degeneration then being a part of the changes of age, from when it occurs in younger patients (Sloper and Storey, 1953). In young patients medial degeneration is probably of congenital origin. Evidence for this view is afforded by the occasional occurrence of dissecting aneurysm in children and the association with developmental defects. The frequent association of medial degeneration when it occurs in young patients with developmental defects of the cardiovascular system is the subject of comment by Schnitker and Bayer and by Gore. By far the commonest association is with coarctation. When this association occurs it would seem that the medial degeneration should be regarded as a 
further developmental defect additional to the coarctation and not simply as secondary to the mechanical strain. Medial degeneration and rupture can occur when stenosis is slight and in some cases has occurred distal to the coarctation (Reifenstein, Levine, and Gross, 1947). Less frequently observed congenital defects included bicuspid aortic valves and a patent foramen ovale.

There is an important association between medial degeneration and the syndrome of developmental defects known as Marfan's syndrome. This syndrome includes long slender digits (arachnodactyly), looseness of the joints, and dislocation of the lenses of the eyes. The literature of the relatively few cases that have come to necropsy has been reviewed by Marvel and Genovese (1951) and Goyette and Palmer (1953); further cases not included in these reviews have been reported by Sloper and Storey (1953), Gore (1953), and Whittaker and Sheehan (1954). Out of a total of 40 cases, aneurysms due to medial degeneration were observed in 26,18 being dissecting and eight fusiform. In Marfan's syndrome medial degeneration has usually not become manifest until early

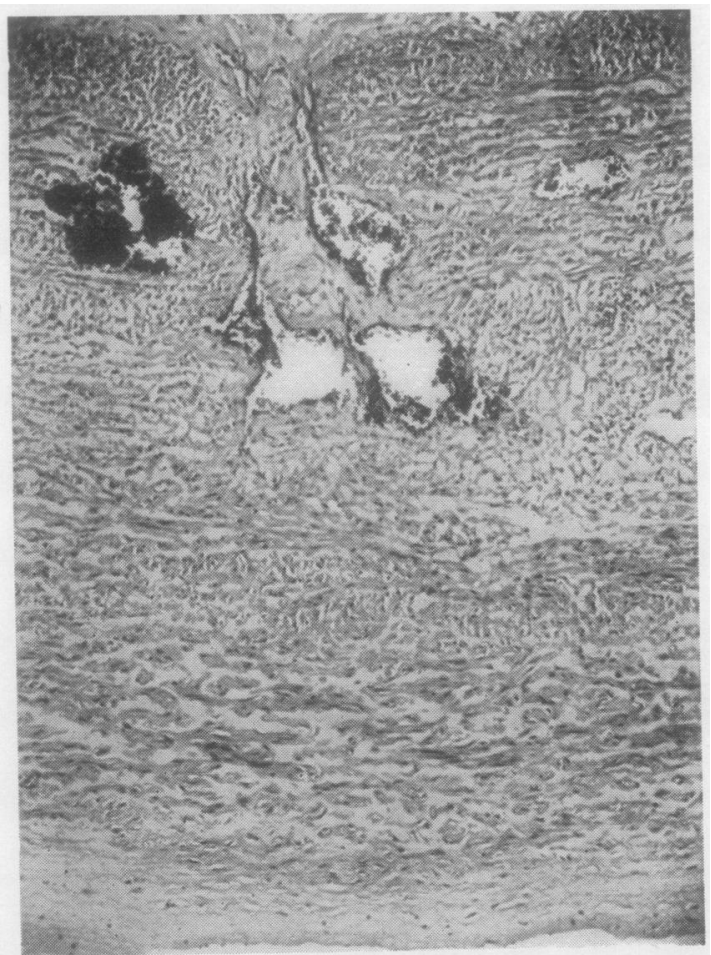

Fig. 5. The wall of the aorta $2 \mathrm{~cm}$. above the valves. Relatively normal smooth muscle fibres separated by empty spaces staining faintly blue. Local dilatations of vasa vasorum and an area of interstitial haemorrhage $(\times 75$ haematoxylin and eosin).

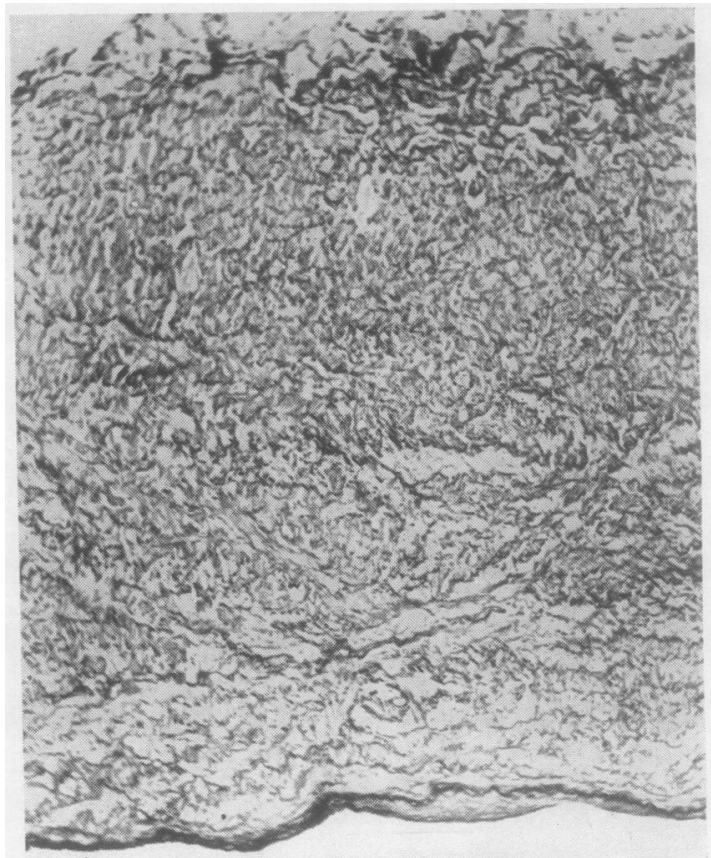

Fig. 6. The wall of the pulmonary artery just above the valves. Separation and fragmentation of the elastic fibres $(\times 75$ Weigert'sO elastic stain and neutral red).

adult life; in all cases but one, rupture of an aneurysm did not take place until after the patients had reached 20 years of age. However, there was one case of ruptured aneurysm in a girl aged 14 years, and in two other cases in which death occurred in adult life clinical evidence of dilatation of the aorta was noted in childhood. It is also probable that Bronson and Sutherland's case of ruptured aneurysm at the early age of 6 years was an example of Marfan's syndrome. Arachnodactyly was not noted, but the report refers to looseness of the joints, chest deformities, a high arched palate, and an unusually shaped head with prominent ears-all defects that have been described in Marfan's syndrome.

Incomplete examples of the syndrome with lesions restricted to the cardiovascular system can occur, and in such cases the diagnosis can some- $O$ times be made certain by study of the family tree $N$ (Whittaker and Sheehan, 1954). It has indeed N been suggested that many of the cases of dissecting $\omega$ aneurysm that have occurred in young patients were incomplete examples of Marfan's syndrome. The presence of coarctation need not preclude such $\stackrel{\mathbb{D}}{\rightarrow}$ a classification, since in three cases coarctation has $\stackrel{?}{+}$ been found to be associated with Marfan's syn- 0 drome. It should be remembered, however, that $\stackrel{\vec{D}}{\mathbb{D}}$ 
the literature concerned with aneurysm due to medial degeneration in patients under 40 years includes some 200 cases, of which only about 26 have been attributed with certainty to Marfan's syndrome.

In the present case there was good evidence that the medial degeneration was of congenital origin. The aneurysm ruptured at an early age and there were other congenital defects : a patent foramen ovale, a minor degree of coarctation, and a hypoplastic right kidney situated in the pelvis. The stigmata of Marfan's syndrome were not observed. With respect to the eyes, superficial examination was all that was permissible at the necropsy, but the eyes had been carefully examined by an ophthalmic surgeon at the time of the squint operation and on a subsequent occasion one year before her death. No abnormality beyond amblyopia due to the squint was noted. Such inquiries as were possible into the family history were negative, but because of the circumstances of sudden death it was not considered kind to press these inquiries very far. Slender evidence connecting the case with Marfan's syndrome is perhaps afforded by the presence of a patent foramen ovale, since this defect is relatively common in cases of Marfan's syndrome (seven out of 40 cases) whereas it has been discovered infrequently in other cases of dissecting aneurysm in the young (four out of 170 cases). Also, a cord-like thickening along the free margin of the aortic valves somewhat similar to that observed in the present case has been observed in cases of Marfan's syndrome (Sloper and Storey, 1953).

\section{Summary}

A case of dissecting aneurysm of the aorta due to medial degeneration is described in a girl aged 10 years. The rarity of dissecting aneurysms in children is stressed. The aetiology of medial degeneration in the young is briefly discussed with reference to its association with developmental defects, particularly with coarctation and with Marfan's syndrome.

My thanks are due to Dr. F. E. Eddison, H.M. Coroner for W. District, North Riding, Yorks, for permission to publish the case, to Dr. L. G. Boyd for clinical details, and to Mr. W. R. I. Hollingsworth for technical assistance.

\section{REFERENCES}

Bronson, E., and Sutherland, G. A. (1918). Brit. J. Child. Dis., 15, 241. Gardner, E., Galbraith, A. J., and Hardwick, S. W. (1939). Lancet, 2, 1019.

Gore, I. (1953). Arch. Path., Chicago, 55, 1.

Goyette, E. M. and Palmer, P. W. (1953). Circulation, 7, 373.

Horder, T. J. (1908). St Bart's Hosp. Rep., 1907, 43, 57.

Klotz, O., and Simpson, W. (1932). Amer. J. med. Sci., 184, 455.

Marvel, R. J., and Genovese, P. D. (1951). Amer. Heart J., 42, 814.

Oppenheimer, R. (1905). Virchows Arch. path. Anat., 181, 382.

Reifenstein, G. H., Levine, S. A., and Gross, R. E. (1947). Amer Heart J. 33, 146.

Rokitansky, C. von (1838). Med. Jahrbuch Oesterr. Staates, 16, 24.

Rokitansky, K. von (1852). Denkschr. Akad. Wissensch., Wien (math. nat. classe), 4, 41.

Schnitker, M. A., and Bayer, C. A. (1944). Ann. intern. Med., 20, 486. Sloper, J. C., and Storey, G. (1953). Journal of Clinical Pathology, 6, 299.

Wasastjerna, E. (1903). Z. klin. Med., 49, 405

Whittaker, S. R. F., and Sheehan, J. D. (1954). Lancet, 2, 791. 